\title{
Employment and social benefits up to 10 years after breast cancer diagnosis: a population-based study
}

\begin{abstract}
C H Paalman ${ }^{1}$, F E van Leeuwen ${ }^{1}$, N K Aaronson ${ }^{1}$, A G E M de Boer ${ }^{2}$, L van de Poll-Franse ${ }^{3,4}$, H S A Oldenburg ${ }^{5}$ and M Schaapveld ${ }^{\star, 1,3}$

${ }^{1}$ Division of Psychosocial Research and Epidemiology, The Netherlands Cancer Institute, Amsterdam, The Netherlands; ${ }^{2}$ Coronel Institute of Occupational Health, Academic Medical Center, Amsterdam, The Netherlands; ${ }^{3}$ Netherlands Comprehensive Cancer Organisation (IKNL), Utrecht, The Netherlands; ${ }^{4}$ CoRPS- Centre of Research on Psychology in Somatic Diseases, Department of Medical and Clinical Psychology, Tilburg University, The Netherlands and ${ }^{5}$ Department of Surgical Oncology, The Netherlands Cancer Institute, Amsterdam, The Netherlands
\end{abstract}

Background: Little is known about employment outcomes after breast cancer (BC) beyond the first years after treatment.

Methods: Employment outcomes were compared with a general population comparison group ( $N=91593)$ up to 10 years after BC for 26120 patients, diagnosed before age 55 between 2000-2005, with income and social benefits data from Statistics Netherlands. Treatment effects were studied in 14916 patients, with information on BC recurrences and new cancer events.

Results: BC survivors experienced higher risk of losing paid employment (Hazard Ratio (HR): 1.6, 95\% Confidence Interval (95\% Cl) 1.4-1.8) or any work-related event up to 5-7 years (HR 1.5, 95\% $\mathrm{Cl} 1.3-1.6)$ and of receiving disability benefits up to 10 years after diagnosis ( $\mathrm{HR} 2.0,95 \% \mathrm{Cl} 1.6-2.5$ ), with higher risks for younger patients. Axillary lymph node dissection increased risk of disability benefits (HR 1.5, 95\% Cl 1.4-1.7) or losing paid employment (HR 1.3, 95\% Cl 1.2-1.5) during the first 5 years of follow-up. Risk of disability benefits was increased among patients receiving mastectomy and radiotherapy ( $\mathrm{HR} 1.2 ; 95 \% \mathrm{Cl} 1.1-1.3)$ and after chemotherapy (HR 1.7; 95\% Cl 1.5-1.9) during the first 5 years after diagnosis.

Conclusions: BC treatment at least partly explains the increased risk of adverse employment outcomes up to 10 years after BC.

Breast cancer (BC) is the most common malignancy among women in the Western world. About a third of all women diagnosed with $\mathrm{BC}$ is under the age of 55. Prognosis of $\mathrm{BC}$ has improved markedly over the last two decades due to earlier diagnosis and better treatment, with current 10-year BC survival approaching $80 \%$ for patients diagnosed before age 55 (Verdecchia et al, 2007).

With employment rates above $60 \%$ for women in the Netherlands, a large proportion of women diagnosed with BC before age 55 is working. For those confronted with cancer, work offers a sense of control in insecure times (Lilliehorn et al, 2013; Islam et al, 2014). Moreover, work gives meaning to life, may provide distraction from the disease and is positively associated with quality of life (Spelten et al, 2002; Kennedy et al, 2007). Previous studies have shown that $60 \%-93 \%$ of the BC survivors will successfully return to work within the first two years after diagnosis (Bushunow et al, 1995; Satariano and DeLorenze, 1996; Spelten et al, 2002; Maunsell et al, 2004; Bradley et al, 2005; Nieuwenhuijsen et al, 2006). Nonetheless, a meta-analysis showed that BC survivors have a 1.3 -fold (95\% CI 1.1-1.5) higher risk of becoming unemployed compared to the general population (de Boer et al, 2009). A considerable group of BC survivors will face long term disabilities which may greatly impact on their financial position and social well-being (de Boer and

*Correspondence: Dr M Schaapveld; E-mail: m.schaapveld@nki.nl 
Frings-Dresen, 2009; Hauglann et al, 2012). Even in early stage BC, the ability to work was negatively influenced at least up to 5 years after diagnosis (Eaker et al, 2011).

Studies have shown that BC treatment is an important risk factor for impaired work-ability (Bouknight et al, 2006; Balak et al, 2008; de Boer et al, 2008; Lavigne et al, 2008; Yoon et al, 2008; Ahn et al, 2009; Fantoni et al, 2010; Hedayati et al, 2012). Chemoor hormonal therapy and mastectomy have been associated with higher risks of unemployment and lower ability to work within the first years after diagnosis, whereas no such effects were found for radiotherapy (Drolet et al, 2005a; Balak et al, 2008; Eaker et al, 2011; Lindbohm et al, 2011).

Because in most studies on return to work patients were followed for only a short time-period, generally less than five years after treatment, it remains largely unknown what happens after these first years. With the increasing number of young $\mathrm{BC}$ survivors, it is important to understand the effects of $\mathrm{BC}$ and its treatment on employment beyond the first years after diagnosis. The objective of this study was to assess the effects of $\mathrm{BC}$ and its treatment on employment and social benefits in a large, unselected sample of women diagnosed with BC before age 55 up to ten years after $\mathrm{BC}$ diagnosis.

\section{MATERIALS AND METHODS}

Study population and data. We composed a cohort comprising all 26120 women diagnosed with primary invasive BC as their first malignancy before the age of 55 years of age in the Netherlands in the period 2000-2005. Patients were identified through the Netherlands Cancer Registry (NCR). The cohort contained information on tumor characteristics and treatment for the primary $\mathrm{BC}$ as well as all subsequent cancers. Details on the prevailing treatment guidelines in the study period are provided in Supplementary Appendix 1 (Rutgers et al, 2002). We linked the NCR cohort with individual social security data, which included data on individual income, receipt of disability benefits, unemployment benefits and welfare at Statistics Netherlands, using date of birth, sex, the date of BC diagnosis and the numerical part of the patient's postal code at $\mathrm{BC}$ diagnosis. Of all women in the cohort, 23760 (91\%) could be uniquely identified based on these variables. Statistics Netherlands anonymized the linked cohort and made the data available to the researchers by secured remote access. The study protocol was reviewed by the NCR internal review board and Statistics Netherlands and requirement for individual informed consent was waived.

General population control sample. We randomly selected women, frequency-matched on age at diagnosis, from the national population registry for each of the years 2000 to 2005 as comparison group. For each BC patient four women were selected. This general population control sample and the cohort of breast cancer patients were mutually exclusive. This comparison group was also linked with social security data at Statistics Netherlands $(N=91593)$.

\section{Work-related outcomes}

Loss of paid employment. Individual, personal yearly income for each women was available for 1999-2010 and was based on income tax data. We defined loss of paid employment as no income from employment for at least two consecutive years since BC diagnosis, and only considered women who had had income from employment before BC.

Disability Benefits. In the Netherlands, during the first two years of sick leave, the employer continues paying at least $70 \%$ of the employee's last salary (Supplementary Appendix 2). In principle, the employee cannot be fired during this period. There is no national registry that tracks sick days of employees during these first two years. That means that women on sick leave are considered to have an income from employment in these first two years. If a patient is considered unable to work after two years, she is entitled to a disability pension to compensate for salary-loss if the salary loss is $>35 \%$. However, when recovery from an illness is considered unlikely, a disability pension can be obtained from 3 weeks after the first sick-day.

Unemployment Benefits and Social Welfare. In the Netherlands, everyone with paid employment is eligible to receive unemployment benefits, the duration of which depends on the individual's working history. After the maximum duration of unemployment benefits ( 3 years and 3 months), local governments are responsible for the last resort of the Dutch Social Security System: social welfare. Information received from Statistics Netherlands included starting date and stop date of unemployment benefits or welfare.

Combined measure of work-related events. Because social security policies differ between countries, we composed the measure 'any work-related event', reflecting an overall change in employment status based on either loss of paid employment, receipt of disability pension, unemployment benefits or welfare.

BC-subsample. Data on subsequent breast cancer events (local, regional or distal recurrence), collected by the NCR, were available up to 7 years after BC diagnosis for 14916 women without distant metastases at initial BC diagnosis. We studied clinical factors associated with employment outcomes in this subsample.

Statistical analysis. BC stage was based on clinical and pathological information. We classified primary treatment as receipt of chemotherapy (yes/no), hormonal therapy (yes/no), axillary lymph node dissection (yes/no), and receipt of either lumpectomy with radiotherapy, mastectomy with radiotherapy, mastectomy without radiotherapy, or other local therapy. Information on subsequent cancer events in the subsample was categorized (yes/no) as noninvasive $\mathrm{BC}$; invasive $\mathrm{BC}$ localized; invasive $\mathrm{BC}$ metastasized or non-breast second primary malignancy, other than non-melanoma skin cancer.

We compared the prevalence of work-related events from one year prior to diagnosis up to ten years after diagnosis between patients in the BC cohort and the general population sample, and estimated cumulative incidence of work-related events, accounting for death as competing event.

Cox regression was used to compare the risk of work-related events after BC diagnosis between BC patients and population controls, accounting for age, individual income before diagnosis (lowest tertile, middle tertle, highest tertile) and self-employment. Analysis were adjusted for self-employment as protection through insurance against loss of income due to unemployment, sickness and disability is fairly expensive in the Netherlands for selfemployed as this is not organized by the government but largely left to the private sector. We used the first date of the event in the analyses. Because of non-proportional hazards over time, analyses were performed for four separate time intervals: up to 2 years, 2 to 5 years, 5 to 7 years and 7 to 10 years after diagnosis.

We investigated the impact of breast cancer treatment on workrelated outcomes in the $\mathrm{BC}$-subsample using multivariable Cox regression models with age as timescale, and adjusted for income before diagnosis, self-employment and new cancer events. New cancer events were included as time-dependent covariates. All analyses were performed using STATA statistical software (Stata 13, StataCorp LP, College Station, TX, USA). 


\section{RESULTS}

Comparisons with the population control group. Prior to diagnosis, $69.2 \%$ of the $\mathrm{BC}$ survivors and $66.6 \%$ of the population controls had paid employment (Figure 1). The cumulative incidence of paid employment decreased over time more strongly among $\mathrm{BC}$ survivors than among population controls $(P<0.001$, Figure 2 and Supplementary Table 1). The cumulative incidence of loss of paid employment was $51.1 \%$ among BC survivors compared to $46.3 \%$ among population controls after 10 years of follow-up.

Among $\mathrm{BC}$ survivors, the prevalence of receiving disability benefits increased strongly in the first two years after diagnosis from $9.2 \%$ prior to $\mathrm{BC}$ diagnosis to $25.3 \%$ two years later, whereas among population controls the prevalence of disability benefits remained fairly stable $(7.7 \%$ at inclusion and $9.9 \%$ at two years; Figure 1). During follow-up, BC survivors maintained a higher cumulative incidence of disability benefits $(P<0.001$, Figure 2 and Supplementary Table 1). At 10 years of follow-up, the cumulative incidence of obtaining disability benefits was $32.7 \%$ among BC survivors and $14.1 \%$ among population controls.

Before diagnosis, around $3 \%$ of both the BC patients and population controls received unemployment benefits (Figure 1). The cumulative incidence of unemployment benefits did not differ between BC survivors and population controls (Figure 2 and Supplementary Table 1).

Prior to diagnosis $4.6 \%$ of the BC patients and $4.3 \%$ of population controls received social welfare. During follow-up BC patients were at slightly increased risk of receiving welfare $(P<0.001$; Figure 2 and Supplementary Table 1$)$, so that after 10 years of follow-up cumulative incidence of women receiving welfare was $7.9 \%$ among $\mathrm{BC}$ survivors and $7.4 \%$ among the population controls.

After 10 years of follow-up, $65.5 \%$ of the BC patients and $50.6 \%$ of the population controls had experienced at least one of these workrelated events $(P<0.001$, Figure 2 and Supplementary Table 1$)$.

Table 1 compares risks for work-related events among BC survivors to risk among population controls. The risk of loss of personal income was increased in BC survivors up to 5-7 years after BC diagnosis (HR 0-2 years: 1.3 , 95\% CI 1.2-1.3; HR 2-5 years: 2.0, 95\% CI 1.9-2.1; HR 5-7 years $1.6,95 \%$ CI 1.4-1.8), but did not differ from that in population controls 7-10 years after BC diagnosis. Risk was increased to a lesser extent among BC survivors aged 50-55 years compared to $\mathrm{BC}$ patients $<50$ years at diagnosis
$\left(P_{\text {interaction }}<0.001\right)$. Except for the period $7-10$ years after $\mathrm{BC}$ diagnosis, risk of loss of personal income increased with stage (Supplementary Table 2). The effect of income before diagnosis on risk of loss of personal income differed between BC patients and general population controls during the first 5 years of follow-up $\left(P_{\text {interaction }}<0.001\right.$, Supplementary Table 2$)$. Whereas $0-2$ years after diagnosis risk more strongly decreased with income among $\mathrm{BC}$ patients than controls, at 2-5 years risk was higher for BC patients in the second or third tertile of income. Self-employed BC patients had a lower risk of loss of personal income.

BC survivors had a strongly increased risk of obtaining disability benefits, irrespective of follow-up interval. Whereas among controls risks increased with age, BC patients had considerably higher risks at younger ages $\left(P_{\text {interaction }}<0.001\right.$, Table 1 and Supplementary Table 3 ). In the first two years post-diagnosis, the risk of obtaining disability benefits was 13.3-fold increased (95\% CI 9.7-18.1) among women $<35$ years and 7.1-fold increased among women aged 50-55 years with stage I BC. The risk of obtaining disability benefits was still 3.3-fold increased among women $<35$ years and 1.9-fold increased among women aged 45-50 with stage I $\mathrm{BC}$ at 7-10 years of follow-up. Risk of disability benefits increased with higher BC stage in all intervals. Self-employed BC patients less often received disability benefits.

BC survivors had a slightly higher risk of obtaining unemployment benefits in the interval 2-5 years after diagnosis (HR 1.2, 95\% CI 1.1-1.3). Risk did not differ by stage and appeared to be limited to $\mathrm{BC}$ patients in the lower or middle tertile of income (HR 1.3, 95\% CI 1.1-1.5 and HR 1.4, 95\% CI 1.2-1.7, respectively; Supplementary Table 4). BC survivors had a higher risk of obtaining welfare $0-2$ years after diagnosis (HR 0-2 years 1.2 , 95\% CI 1.0-1.5, Table 1 and Supplementary Table 5). Beyond 2 years of follow-up, uptake of welfare benefits did not differ between BC survivors and population controls.

Overall, BC survivors experienced markedly increased risks of any work-related event up to 7 years after diagnosis compared to population controls (HR at 5-7 years: 1.5, 95\% CI 1.3-1.6, Table 1). At 7-10 years of follow-up, risk of a work-related event was only increased for BC survivors, aged 45-50 at diagnosis (HR $1.4,95 \%$ CI 1.2-1.8), whereas BC survivors aged 50-55 at diagnosis even had a somewhat lower risk of experiencing a work-related event (HR 0.8, 95\% CI 0.7-1.0). Risk of any work-related event increased with stage and with tertile of personal income before BC diagnosis for the first 5 years after BC diagnosis (Supplementary Table 6).

\section{A}

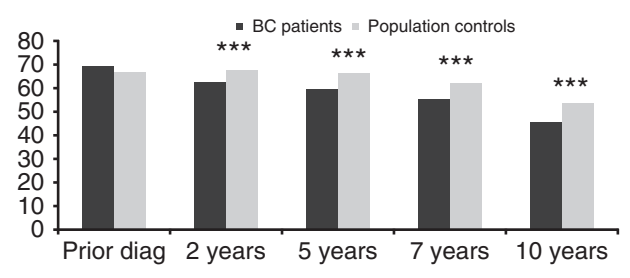

C

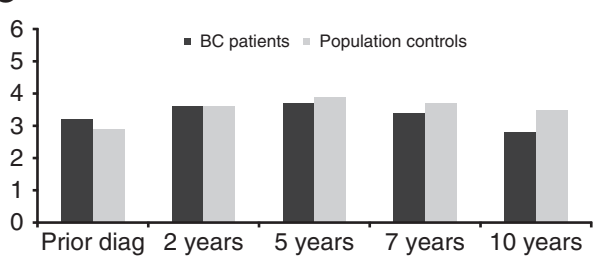

B

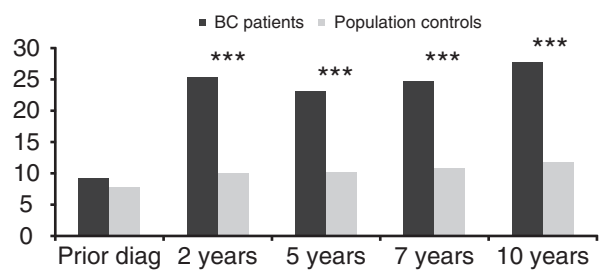

D

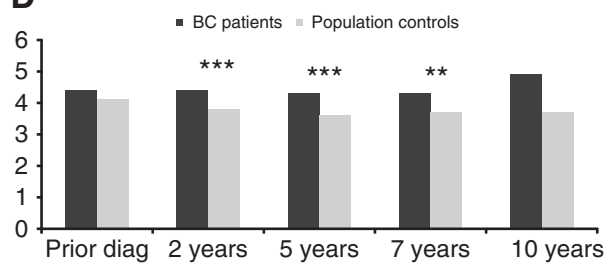

Figure 1. Prevalence of work-related outcomes in BC survivors and the general population comparison sample in the year prior to $B C$ diagnosis and at 2,5,7 and 10 years of follow-up. (A) \% women with income from employment. (B) \% women with disability benefits. (C) \% women with unemployment benefits. (D) \% women on welfare. ${ }^{\star} P<0.05$; ${ }^{\star \star} P<0.01 ;{ }^{\star \star \star} P<0.001$. 

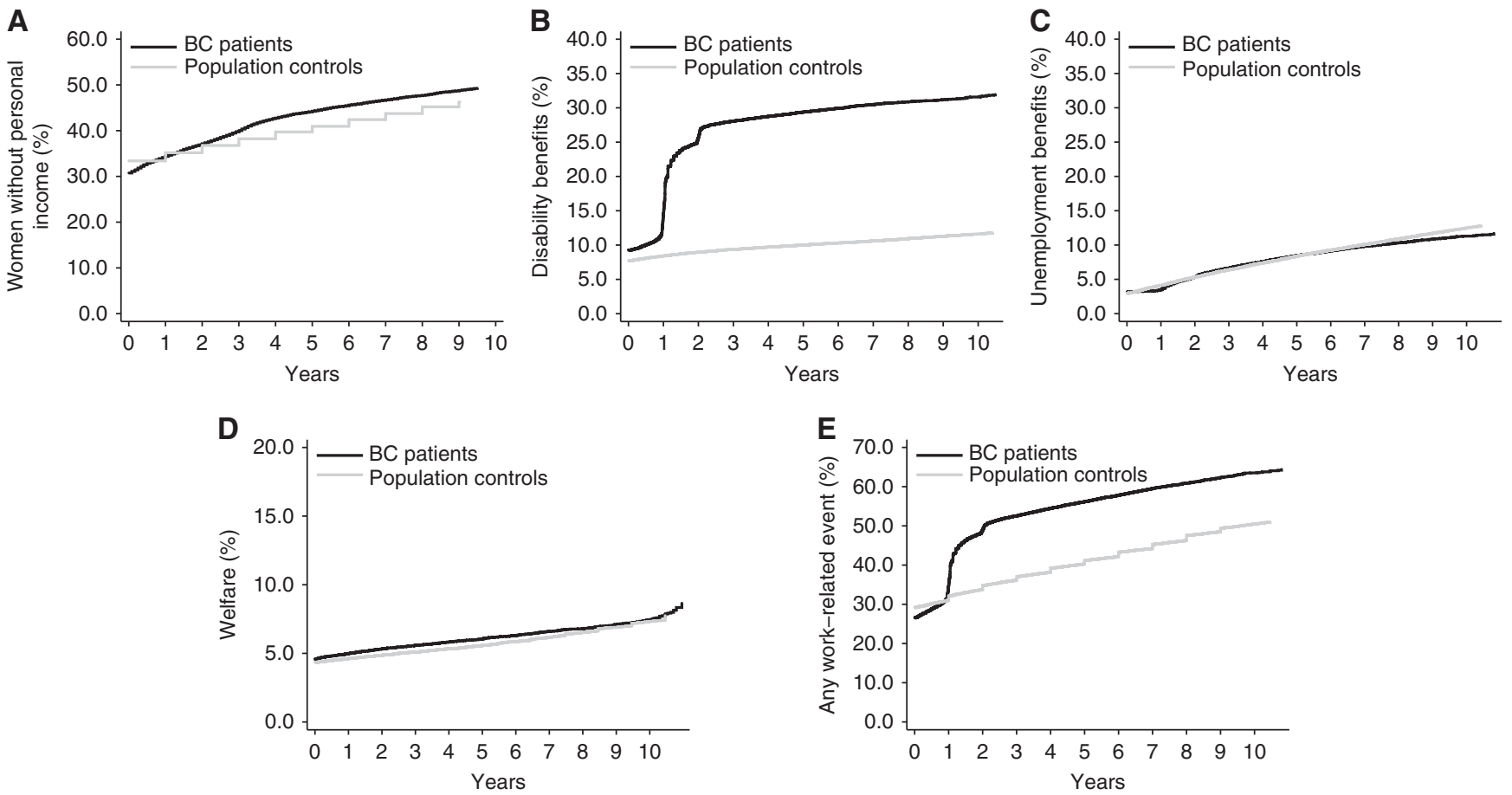

Figure 2. Cumulative incidence of losing paid employment and the uptake of social benefits during follow-up in BC patients and general population controls. (A) Loss of personal income. (B) Disability benefits. (C) Unemployment benefits. (D) Welfare. (E) Any work-related event.

Table 1. Risk (HR) of work-related outcomes after diagnosis: BC survivors compared to general population controls by time since breast cancer diagnosis and age

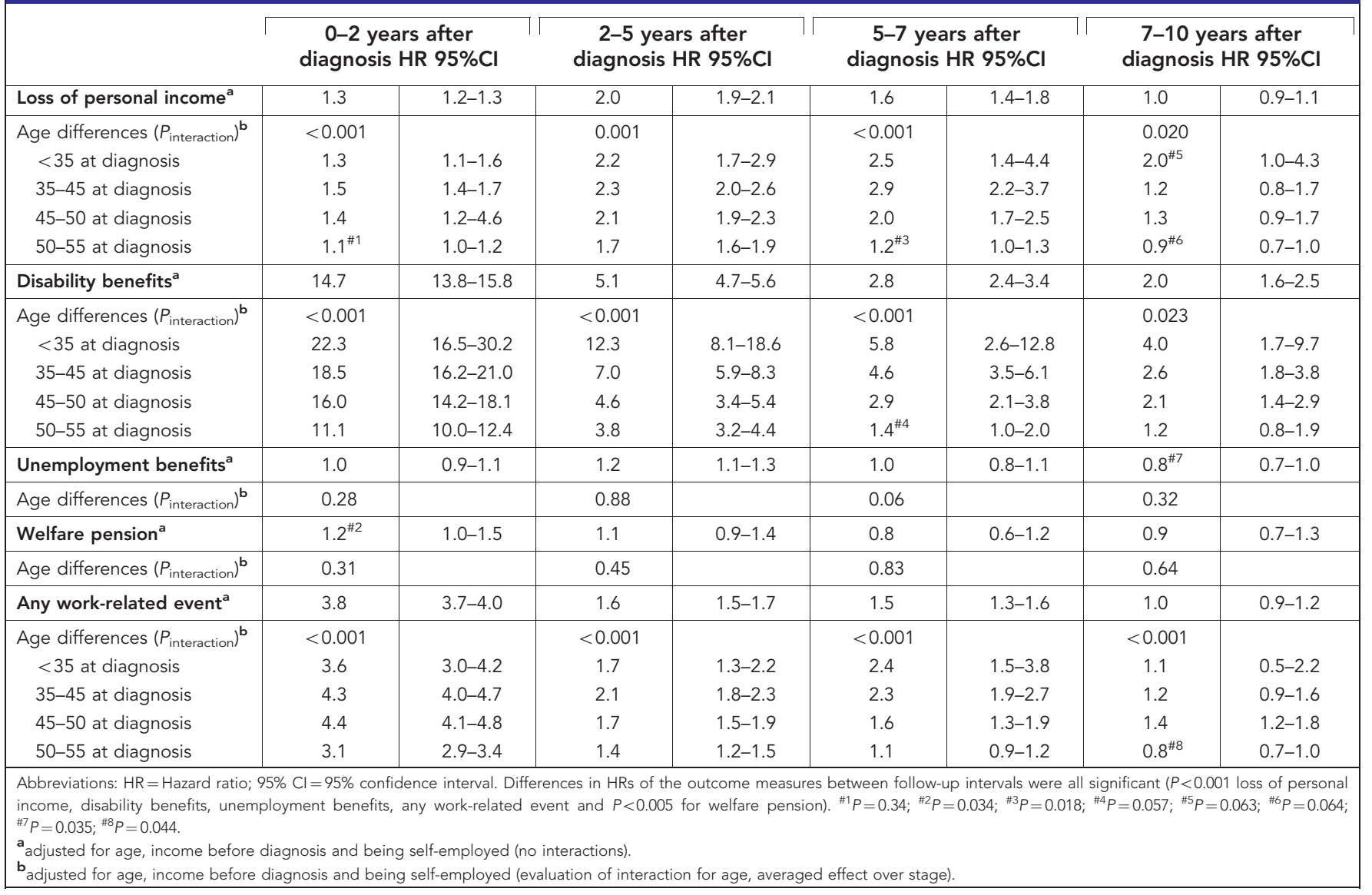

Effects of treatment: Within cohort comparisons. The subcohort $(N=14916)$, in which effects of treatment were investigated did not differ from other BC survivors other than by initial stage (Supplementary Table 7). Treatment differed by age with BC patients $<35$ years women more often receiving mastectomy followed by radiotherapy, axillary dissection and chemotherapy 
than BC patients aged 50-55 years (Supplementary Table 8). Compared to women treated with lumpectomy followed by radiotherapy and adjusted for age, time since diagnosis, individual income before diagnosis, self-employment and subsequent cancer events, women treated with mastectomy followed by radiotherapy had a higher risk of obtaining disability benefits (HR 1.2, 95\% CI 1.1-1.3) or any work-related event (HR 1.1, 95\% CI 1.0-1.2) (Table 2). Axillary lymph node dissection was associated with increased risk of loss of personal income up to 5 years after diagnosis (HR 1.3, 95\% CI 1.2-1.5) but not thereafter, as well as with obtaining disability benefits (HR 1.5, 95\% CI 1.4-1.7) and any work-related event (HR 1.4, 95\% CI 1.3-1.5).

Chemotherapy was associated with increased risk of obtaining disability benefits (HR 1.7, 95\% CI 1.5-1.9) and any work-related event (HR 1.4, 95\% CI 1.2-1.5) during the first 5 years after diagnosis. Women treated with mastectomy followed by radiotherapy had, on the other hand, a lower risk of obtaining unemployment benefits compared to women treated with lumpectomy followed by radiotherapy (HR 0.8, 95\% CI 0.6-1.0). Women treated with hormonal therapy had lower risk of any work-related event than women not treated with hormonal therapy (HR 0.9, 95\% CI 0.8-1.0).

\section{DISCUSSION}

This nationwide population-based study showed that BC survivors experienced increased risk of obtaining disability benefits up to ten years after diagnosis, increased risk of loss of paid employment up to 7 years after diagnosis and increased risk of obtaining unemployment benefits up to five years after diagnosis. The magnitude of risk of adverse work-related outcomes differed by age, with women diagnosed before 35 years of age having the highest risk of obtaining disability benefits and women aged 35-45 having the highest risk of obtaining unemployment benefits. BC survivors treated with mastectomy followed by radiotherapy, chemotherapy or axillary lymph node dissection experienced higher risk of adverse employment outcomes, other than unemployment.

Previously de Boer et al (2009) found a 1.3-fold increased risk of unemployment among BC survivors. We found a smaller, 1.2-fold increased risk of obtaining unemployment benefits, limited to the period 2-5 years after diagnosis. This may be explained by differences in the definition of unemployment in both studies and the fact that the meta-analysis by de Boer and colleagues included studies from various countries with a diversity of social security systems. While in the meta-analysis various work-related outcomes such as sick leave and disability benefits were combined into one measure 'not being employed', in contrast our study only considered women who actually received unemployment benefits. Our results for any work-related event, which probably better resembles the outcome used in the meta-analyses, however showed much higher risks.

In the first two years after BC diagnosis we found no increased risks of receiving unemployment benefits, which may reflect Dutch regulations (Sharp and Timmons, 2011; Gimeno et al, 2014). However, beyond 2 years after diagnosis BC survivors, and particularly those aged 35-45 at diagnosis, do appear to experience increased risk of losing their job. Life course specific factors, such as having young children at the time of $\mathrm{BC}$ diagnosis, may at least partly explain these differences in risk with age.

Although several previous studies observed higher risks of adverse employment outcomes with older age at diagnosis (Drolet et al, 2005a; Carlsen et al, 2008; Hassett et al, 2009; Islam et al, 2014) we found, in general, higher risks among women younger than 45 years at diagnosis. Although it may be expected that a serious illness such as breast cancer is associated with adverse employment outcomes, even 7-10 years after diagnosis the risk of obtaining disability benefits remains increased, particularly among younger $\mathrm{BC}$ patients. $\mathrm{BC}$ and its treatment is often more aggressive at younger ages and young BC survivors may therefore also face more severe long-term adverse effects, including those which are work-related (Bloom et al, 2013). In addition, age-differences regarding survivorship issues have been reported. For instance, Ganz and colleagues found that younger BC survivors reported more impact of cancer on a range of life plans and activities, including working life, 5-10 years after diagnosis, compared to older women (Ganz et al, 2002). It is therefore important to further investigate the needs of women in specific age groups to enhance sustainable return to work and to prevent these women from dropping out of the labor market long after their treatment has ended.

In line with previous studies (Drolet et al, 2005b; Balak et al, 2008; Ahn et al, 2009; Johnsson et al, 2009; Hassett et al, 2009; Fantoni et al, 2010; Johnsson et al, 2010; Blinder et al, 2012; Hedayati et al, 2012; Jagsi et al, 2014), we found that patients treated with mastectomy followed by radiotherapy, axillary lymph

Table 2. Associations of treatment for primary BC with work-related outcomes after BC in the BC subsample

\begin{tabular}{|c|c|c|c|c|c|c|c|c|c|c|c|c|}
\hline & \multicolumn{3}{|c|}{ Loss of personal income } & \multicolumn{3}{|c|}{ Disability benefits } & \multicolumn{3}{|c|}{ Unemployment benefits } & \multicolumn{3}{|c|}{ Any work-related event } \\
\hline & Tot/event* & $\mathrm{HR}^{\star *}$ & $95 \% \mathrm{Cl}$ & Tot/event & HR & $95 \% \mathrm{Cl}$ & Tot/event & HR & $95 \% \mathrm{Cl}$ & Tot/event & HR & $95 \% \mathrm{Cl}$ \\
\hline \multicolumn{13}{|l|}{ Surgery } \\
\hline 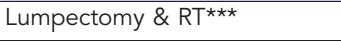 & $5920 / 1275$ & 1.0 & Ref & $6997 / 1278$ & 1.0 & Ref & $7216 / 553$ & 1.0 & Ref & $4841 / 1794$ & 1.0 & Ref \\
\hline Mastectomy & $2965 / 652$ & 1.0 & $0.9-1.1$ & $3653 / 717$ & 1.0 & $0.9-1.1$ & $3814 / 267$ & 0.9 & $0.8-1.1$ & $2425 / 971$ & $1.0^{\# 6}$ & $1.0-1.1$ \\
\hline Mastectomy \& RT & $1940 / 474$ & $1.1^{\# 1}$ & $1.0-1.3$ & $2384 / 701$ & 1.2 & $1.1-1.3$ & $2488 / 130$ & $0.8^{\# 4}$ & $0.6-1.0$ & $1582 / 754$ & $1.1^{\# 7}$ & $1.0-1.2$ \\
\hline Axillary lymph node dissection & $6463 / 1535$ & & & $7930 / 1975$ & 1.5 & $1.4-1.7$ & $8242 / 557$ & $1.1^{\# 5}$ & $1.0-1.3$ & $5315 / 2364$ & & \\
\hline $\begin{array}{l}<5 \text { years after diagnosis } \\
>5 \text { years after diagnosis }\end{array}$ & & $\begin{array}{l}1.3 \\
0.8^{\# 2}\end{array}$ & $\begin{array}{l}1.2-1.5 \\
0.6-1.0\end{array}$ & & & & & & & & $\begin{array}{l}1.4 \\
1.0\end{array}$ & $\begin{array}{l}1.3-1.5 \\
0.8-1.3\end{array}$ \\
\hline Chemotherapy & $7019 / 1560$ & 1.0 & $0.9-1.2$ & & & & $8601 / 582$ & 0.9 & $0.8-1.1$ & $5745 / 2466$ & & \\
\hline $\begin{array}{l}<5 \text { years after diagnosis } \\
>5 \text { years after diagnosis }\end{array}$ & & & & & $\begin{array}{l}1.7 \\
1.0\end{array}$ & $\begin{array}{l}1.5-1.9 \\
0.7-1.3\end{array}$ & & & & & $\begin{array}{l}1.4 \\
1.0\end{array}$ & $\begin{array}{l}1.2-1.5 \\
0.8-1.2\end{array}$ \\
\hline Hormone therapy & $4899 / 1132$ & 1.0 & $0.9-1.1$ & $5839 / 1362$ & $0.9^{\# 3}$ & $0.9-1.0$ & $6067 / 403$ & 0.9 & $0.8-1.1$ & $4019 / 1663$ & $0.9^{\# 8}$ & $0.8-1.0$ \\
\hline \multicolumn{13}{|c|}{$\begin{array}{l}\text { Abbreviations: }{ }^{*} \text { Tot }=\text { total; }{ }^{* \star} \mathrm{HR}=\text { hazard ratio; } 95 \% \mathrm{Cl}=95 \% \text { confidence interval; }{ }^{* \star *} \mathrm{RT}=\text { radiotherapy. Note1: Model adjusted for age (time scale, continuous), time since diagnosis }(0-2, \\
2-5,5-7 \text { and } \geqslant 7 \text { years), self-employment, individual income before diagnosis (tertiles) and new (breast) cancer events (time-varying). Data for subsequent breast events (loco-regional } \\
\text { recurrence and/or distant metastases) were available up to } 6 \text { years after diagnosis, data for new cancer events (including newly diagnosed ipsilateral or contralateral breast cancer) up to } 10 \text { year } \\
\text { after diagnosis. }{ }^{\# 1} P=0.051 ;{ }^{\# 2} P=0.10 ;{ }^{\# 3} P=0.12 ;{ }^{\# 4} P=0.011 ;{ }^{\# 5} P=0.15 ;{ }^{\# 6} P=0.47 ;{ }^{\# 7} P=0.018 ;\end{array}$} \\
\hline
\end{tabular}


node dissection or chemotherapy had higher risk of various workrelated events, even after accounting for new cancer events. Mastectomy followed by radiotherapy and axillary lymph node dissection may influence working life long after treatment due to increased risk of chronic pain and lymphedema (Nesvold et al, 2010; Eaker et al, 2011). Although many side effects of chemotherapy are temporary (Eaker et al, 2011), studies have found that chemotherapy may impact on cognitive functioning (de Ruiter et al, 2011) and fatigue (Reinertsen et al, 2010) up to 10 years after diagnosis. Both cognitive functioning and fatigue have been associated with impaired work functioning (Islam et al, 2014). Further research is needed on underlying mechanisms causing long-term treatment side effects and their impact on employment.

In contrast to previous studies (Eaker et al, 2011; Islam et al, 2014), we found no increased risk of adverse work-related events after hormonal therapy. Most of these studies only assessed the effects on (short-term) sickness absence whereas in our study women were followed up to ten years after BC diagnosis. Women with hormone sensitive tumors have better overall prognoses and may less often need to obtain disability benefits.

As we accounted for new (breast) cancer events and the treatment effects appeared independent of subsequent (breast) cancer events, the effects of treatment we found do not merely reflect the underlying differences in stage.

Strengths and limitations. Some limitations need to be considered when interpreting the results. First of all, we acknowledge that we present many significance tests and therefore caution against overinterpretation of our findings, especially when based on $P$-values $>0.001$. Furthermore, our study does reflect the Dutch social benefits and welfare system and therefore our results may not be fully generalizable to other countries in the European Union, let alone farther afield. In general, the structure of social security legislation in the Netherlands does provide reasonable protection to Dutch employees which may be less so elsewhere. The vulnerable position of young women has, however, been found in other countries as well, which may indicate that BC survivors share risk factors transcending mere effects of social security systems. Furthermore, our results need to be interpreted within the context of a continuously changing landscape, due to changes in both $\mathrm{BC}$ treatment and work-related legislation. Further research could focus on the impact of legislation on adverse work-related outcomes in order to improve the employment position of BC survivors.

Data on subsequent cancer events were only available for a part of our BC cohort. However, again our data did not provide any indication that the sub-cohort differed from other BC survivors other than by initial stage (women with tumor stage IV were not followed-up by the NCR). Furthermore, our study lacked information on reasons for losing paid employment and we have no information on, for instance, perceived work ability of the women in our study. In order to enhance sustainable work among BC survivors, more detailed information from BC survivors and other stakeholders, such as their employer and their colleagues is needed. Therefore the present study was followed-up by a survey study in order to gain more insight in factors hampering or facilitating employment after BC.

Nonetheless, this is one among few studies to evaluate adverse work-related events in a large, population-based cohort of fairly recently treated $\mathrm{BC}$ survivors beyond the first 5 years after initial BC treatment, with good quality data on initial treatment (Carlsen et al, 2008; Hauglann et al, 2012). We used highly reliable, high quality social security data from Dutch government institutions to identify identified work-related events using, instead of relying on self-reported outcomes, resulting in unbiased information. Furthermore, this study took new BC events into account when evaluating the effect of $\mathrm{BC}$ and its treatment on work-related outcomes.
Since many BC survivors will experience work-related problems and considering the fact that work is an important aspect of rehabilitation, work and return to work should be a standard topic to discuss after completion of treatment. Oncologists should timely refer patients, whenever patients may need support with work reintegration. In the Netherlands, several innovative rehabilitation programs are being initiated to improve the occupational rehabilitation of breast cancer patients, including support of occupational physicians with a specialised training in oncological issues (Zaman et al, 2015) and hospital-based work support interventions (Tamminga et al, 2013).

\section{ACKNOWLEDGEMENTS}

Funding: This work was supported by Pink Ribbon [2011.WO17.C102]. The funding party had no role in study design, in the collection, analysis, and interpretation of data, in the writing of the report, nor in the decision to submit the article for publication.

\section{CONFLICT OF INTEREST}

The authors declare no conflict of interest.

\section{AUTHORS CONTRIBUTORS}

Contributorship statement: FEvL, NKA, and MS were responsible for the study concept and design and obtained funding. CHP and MS acquired and analyzed the data. CHP, MS, FEvL and NKA interpreted the data. CHP and MS drafted the manuscript, which was critically revised for important intellectual content by all authors. All authors commented on and approved the final draft. MS is guarantor of the study. All authors had full access to all of the data in the study and take responsibility for the integrity of the data and the accuracy of the data analysis.

\section{REFERENCES}

Ahn E, Cho J, Shin DW, Park BW, Ahn SH, Noh DY, Nam SJ, Lee ES, Yun YH (2009) Impact of breast cancer diagnosis and treatment on work-related life and factors affecting them. Breast Cancer Res Treat 116(3): 609-616.

Balak F, Roelen CA, Koopmans PC, Ten Berge EE, Groothoff JW (2008) Return to work after early-stage breast cancer: a cohort study into the effects of treatment and cancer-related symptoms. J Occup Rehabil 18(3): 267-272.

Blinder VS, Patil S, Thind A, Diamant A, Hudis CA, Basch E, Maly RC (2012) Return to work in low-income Latina and non-Latina white breast cancer survivors: a 3-year longitudinal study. Cancer 118(6): 1664-1674.

Bloom JR, Stewart SL, Napoles AM, Hwang ES, Livaudais JC, Karliner L, Kaplan CP (2013) Quality of life of Latina and Euro-American women with ductal carcinoma in situ. Psychooncology 22(5): 1008-1016.

Bouknight RR, Bradley CJ, Luo Z (2006) Correlates of return to work for breast cancer survivors. J Clin Oncol 24(3): 345-353.

Bradley CJ, Neumark D, Bednarek HL, Schenk M (2005) Short-term effects of breast cancer on labor market attachment: results from a longitudinal study. J Health Econ 24(1): 137-160.

Bushunow PW, Sun Y, Raubertas RF, Rosenthal S (1995) Adjuvant chemotherapy does not affect employment in patients with early-stage breast cancer. J Gen Intern Med 10(2): 73-76.

Carlsen K, Dalton SO, Diderichsen F, Johansen C (2008) Risk for unemployment of cancer survivors: A Danish cohort study. Eur J Cancer (Oxford, England: 1990) 44(13): 1866-1874.

de Boer AG, Frings-Dresen MH (2009) Employment and the common cancers: return to work of cancer survivors. Occup Med (Oxford, England) 59(6): $378-380$

de Boer AG, Taskila T, Ojajarvi A, van Dijk FJ, Verbeek JH (2009) Cancer survivors and unemployment: a meta-analysis and meta-regression. JAMA 301(7): 753-762. 
de Boer AG, Verbeek JH, Spelten ER, Uitterhoeve AL, Ansink AC, de Reijke TM, Kammeijer M, Sprangers MA, van Dijk FJ (2008) Work ability and return-towork in cancer patients. Br J Cancer 98(8): 1342-1347.

de Ruiter MB, Reneman L, Boogerd W, Veltman DJ, Van Dam FS, Nederveen AJ, Boven E, Schagen SB (2011) Cerebral hyporesponsiveness and cognitive impairment 10 years after chemotherapy for breast cancer. Hum Brain Mapp 32(8): 1206-1219.

Drolet M, Maunsell E, Brisson J, Brisson C, Masse B, Deschenes L (2005a) Not working 3 years after breast cancer: predictors in a population-based study. J Clin Oncol 23(33): 8305-8312.

Drolet M, Maunsell E, Mondor M, Brisson C, Brisson J, Masse B, Deschenes L (2005b) Work absence after breast cancer diagnosis: a population-based study. CMAJ 173(7): 765-771.

Eaker S, Wigertz A, Lambert PC, Bergkvist L, Ahlgren J, Lambe M (2011) Breast cancer, sickness absence, income and marital status. A study on life situation 1 year prior diagnosis compared to 3 and 5 years after diagnosis. PLoS One 6(3): e18040.

Fantoni SQ, Peugniez C, Duhamel A, Skrzypczak J, Frimat P, Leroyer A (2010) Factors related to return to work by women with breast cancer in northern France. J Occup Rehabil 20(1): 49-58.

Ganz PA, Desmond KA, Leedham B, Rowland JH, Meyerowitz BE, Belin TR (2002) Quality of life in long-term, disease-free survivors of breast cancer: a follow-up study. J Natl Cancer Inst 94(1): 39-49.

Gimeno D, Bultmann U, Benavides FG, Alexanderson K, Abma FI, Ubalde-Lopez M, Roelen CA, Kjeldgard L, Delclos GL (2014) Cross-national comparisons of sickness absence systems and statistics: towards common indicators. Eur J Public Health 24(4): 663-666.

Hassett MJ, O'Malley AJ, Keating NL (2009) Factors influencing changes in employment among women with newly diagnosed breast cancer. Cancer 115(12): 2775-2782.

Hauglann B, Benth JS, Fossa SD, Dahl AA (2012) A cohort study of permanently reduced work ability in breast cancer patients. J Cancer Surviv 6(3): 345-356

Hedayati E, Johnsson A, Alinaghizadeh H, Schedin A, Nyman H, Albertsson M (2012) Cognitive, psychosocial, somatic and treatment factors predicting return to work after breast cancer treatment. Scand J Caring Sci 27(2): 380-387.

Islam T, Dahlui M, Majid H, Nahar A, Mohd Taib N, Su T (2014) Factors associated with return to work of breast cancer survivors: a systematic review. BMC Public Health 14(Suppl 3): S8.

Jagsi R, Hawley ST, Abrahamse P, Li Y, Janz NK, Griggs JJ, Bradley C, Graff JJ, Hamilton A, Katz SJ (2014) Impact of adjuvant chemotherapy on longterm employment of survivors of early-stage breast cancer. Cancer 120(12): 1854-1862.

Johnsson A, Fornander T, Rutqvist LE, Olsson M (2010) Factors influencing return to work: a narrative study of women treated for breast cancer. Eur J Cancer Care (Engl) 19(3): 317-323.

Johnsson A, Fornander T, Rutqvist LE, Vaez M, Alexanderson K, Olsson M (2009) Predictors of return to work ten months after primary breast cancer surgery. Acta Oncologica (Stockholm, Sweden) 48(1): 93-98.

Kennedy F, Haslam C, Munir F, Pryce J (2007) Returning to work following cancer: a qualitative exploratory study into the experience of returning to work following cancer. Eur J Cancer Care (Engl) 16(1): 17-25.

Lavigne JE, Griggs JJ, Tu XM, Lerner DJ (2008) Hot flashes, fatigue, treatment exposures and work productivity in breast cancer survivors. $J$ Cancer Surviv 2(4): 296-302.
Lilliehorn S, Hamberg K, Kero A, Salander P (2013) Meaning of work and the returning process after breast cancer: a longitudinal study of 56 women. Scand J Caring Sci 27(2): 267-274.

Lindbohm ML, Kuosma E, Taskila T, Hietanen P, Carlsen K, Gudbergsson S, Gunnarsdottir H (2011) Cancer as the cause of changes in work situation (a NOCWO study). Psychooncology 20(8): 805-812.

Maunsell E, Drolet M, Brisson J, Brisson C, Masse B, Deschenes L (2004) Work situation after breast cancer: results from a population-based study. J Natl Cancer Inst 96(24): 1813-1822.

Nesvold IL, Fossa SD, Holm I, Naume B, Dahl AA (2010) Arm/shoulder problems in breast cancer survivors are associated with reduced health and poorer physical quality of life. Acta Oncologica (Stockholm, Sweden) 49(3): 347-353.

Nieuwenhuijsen K, Bos-Ransdorp B, Uitterhoeve LL, Sprangers MA, Verbeek JH (2006) Enhanced provider communication and patient education regarding return to work in cancer survivors following curative treatment: a pilot study. J Occup Rehabil 16(4): 647-657.

Reinertsen KV, Cvancarova M, Loge JH, Edvardsen H, Wist E, Fossa SD (2010) Predictors and course of chronic fatigue in long-term breast cancer survivors. J Cancer Surviv 4(4): 405-414.

Rutgers EJ, Nortier JW, Tuut MK, van Tienhoven G, Struikmans H, Bontenbal M, von Meyenfeldt MF, Vreugdenhil G, Benraadt T, Garssen B, Peterse JL. Nationaal Borstkanker Overleg Nederland; Kwaliteitsinstituut voor de Gezondheidszorg (2002) Dutch Institute for Healthcare Improvement guideline, "Treatment of breast cancer". Ned Tijdschr Geneeskd 146: 2144-2151.

Satariano WA, DeLorenze GN (1996) The likelihood of returning to work after breast cancer. Public Health Rep 111(3): 236-241.

Sharp L, Timmons A (2011) Social welfare and legal constraints associated with work among breast and prostate cancer survivors: experiences from Ireland. J Cancer Surviv 5(4): 382-394.

Spelten ER, Sprangers MA, Verbeek JH (2002) Factors reported to influence the return to work of cancer survivors: a literature review. Psychooncology 11(2): 124-131.

Tamminga SJ, Verbeek JH, Bos MM, Fons G, Kitzen JJ, Plaisier PW, FringsDresen MH, de Boer AG (2013) Effectiveness of a hospital-based work support intervention for female cancer patients - a multi-centre randomised controlled trial. PLoS One 8(5): e63271.

Verdecchia A, De Angelis R, Francisci S, Grande E (2007) Methodology for estimation of cancer incidence, survival and prevalence in Italian regions. Tumori 93(4): 337-344.

Yoon J, Malin JL, Tao ML, Tisnado DM, Adams JL, Timmer MJ, Ganz PA, Kahn KL (2008) Symptoms after breast cancer treatment: are they influenced by patient characteristics? Breast Cancer Res Treat 108(2): 153-165.

Zaman AC, Bruinvels DJ, de Boer AG, Frings-Dresen MH (2015) Supporting cancer patients with work-related problems through an oncological occupational physician: a feasibility study. Eur J Cancer Care (Engl); e-pub ahead of print 31 August 2015; doi:10.1111/ecc.12378.

(c) (1) (2) This work is licensed under the Creative Commons (c) Attribution-Non-Commercial-Share Alike 4.0 International License. To view a copy of this license, visit http:// creativecommons.org/licenses/by-nc-sa/4.0/

Supplementary Information accompanies this paper on British Journal of Cancer website (http://www.nature.com/bjc) 